\title{
Cul de Sac : An Unusual Presentation of Giant Cell Arteritis
}

\author{
Chinenye Osuorji ${ }^{1}$, Naomi Ojumah ${ }^{2}$, Oluwafeyi Adedoyin ${ }^{3}$, Okechukwu Okoye ${ }^{4}$, Ikechukwu Mbonu ${ }^{5}$ \\ 1. Internal Medicine, Burrell College of Osteopathic Medicine, Las Cruces, USA 2. Anatomical Sciences, St. George's \\ University School of Medicine, St. George's, GRD 3. Internal Medicine, Englewood Hospital and Medical Center, \\ Englewood, USA 4. Internal Medicine, Newark Beth Israel Medical Center, Newark, USA 5. Rheumatology, Medical \\ College of Wisconsin, Milwaukee, USA
}

Corresponding author: Naomi Ojumah, nojumah1@sgu.edu

\begin{abstract}
Giant cell arteritis (GCA), previously referred to as temporal arteritis, continues to pose significant diagnostic challenges to clinicians as it could have unusual and atypical presentations. We present the case of a 69-year-old Caucasian male who had presented with painful scrotal swelling and bilateral arm pain and was eventually diagnosed with GCA based on histological findings. His symptoms resolved completely with the initiation of high-dose steroids. It is important to note that some clinical manifestations of GCA could be subtle, atypical, and maybe entirely extracranial. A high index of suspicion is helpful when diagnosing patients who present with non-specific or constitutional symptoms as delay in diagnosis or treatment in these patients could result in severe adverse outcomes.
\end{abstract}

Review began 06/21/2021 Review ended 06/30/2021 Published 07/13/2021

\section{๑) Copyright 2021}

Osuorji et al. This is an open access article distributed under the terms of the Creative Commons Attribution License CC-BY 4.0., which permits unrestricted use, distribution, and reproduction in any medium, provided the original author and source are credited.
Categories: Internal Medicine, Rheumatology

Keywords: giant cell arteritis, large vessel vasculitis, clinical diagnosis, polymyalgia rheumatica, glucocorticoids, temporal artery biopsy, autoimmue

\section{Introduction}

Giant cell arteritis (GCA) is a chronic granulomatous vasculitis that affects medium and large blood vessels [1]. Major vessels include the aorta and its extracranial branches. These include the external carotid arteries and its tributaries such as the temporal and occipital arteries. Other arteries include the ophthalmic, vertebral, subclavian, axillary, thoracic, and abdominal aorta in some cases. It has an incidence of about 1525 cases per 100,100 persons and tends to affect older individuals of 50 years and above [1,2].

The clinical manifestation of GCA could be sudden onset or insidious. Most described symptoms include scalp tenderness and headaches in $70-80 \%$ of cases, and hearing loss, jaw claudication, and sudden onset of unilateral visual loss in 10-15\% of cases [2]. Timely diagnosis and management of GCA is pivotal, especially with ophthalmic involvement, which may result in the most dreaded complication of irreversible vision loss. Preceding events of temporary vision loss have been linked to a greater risk for permanent visual compromise $[1,2]$. In addition, less common complications of episcleritis, scleritis, and extraocular muscular paralysis have been cited [3].

Polymyalgia rheumatica is often diagnosed in association with GCA. Non-specific, constitutional symptoms have also been described. These include low-grade fever, malaise, weight loss, anorexia, and generalized fatigue. Although very rare, symptoms suggestive of peripheral neuropathy, strokes, and ischemic complications involving the tongue, scalp, and extremities have also been described. Examination of the temporal region may reveal thickened, cord-like, beaded, diminished, or non-pulsatile vasculature with or without associated tenderness. Careful assessment of other peripheral arterial regions should be assessed and may yield similar findings. Aortitis can be complicated by dissection and aneurysm involving most commonly the thoracic aorta [4-6]. Known urological manifestations of GCA have also been reported as orchitis, epididymitis, as well as testicular mass [7-9].

\section{Case Presentation}

A 69-year-old man with a history of type 2 diabetes mellitus and hypertension presented to the emergency room with hyperglycemia and complaints of a painful scrotal swelling of four days. He had been riding a snow-mobile for the past week but denied any trauma. He has no history of penile discharge, dysuria, hematuria, and urinary frequency or urgency and reports normal bladder emptying and bowel movement. Vitals were otherwise within normal limits. On physical examination, he was obese with a BMI of 34.8, and had Dupuytren's contracture on the left hand. Eye examination was remarkable for bilateral cataracts. Bilateral hydrocele with tenderness was noted. There was no erythema, warmth, rash, or skin excoriation. The rest of his physical examination was unremarkable.

The patient returned to the emergency room a month later with complaints of worsening dyspnea and 


\section{Cureus}

generalized weakness. Preliminary pulmonary and cardiac workup was largely unremarkable. However, newonset thrombocytosis, anemia, and leukocytosis were reported. Findings of CT of the chest, abdomen, and pelvis were not suggestive of any acute or chronic pulmonary process, malignancy, infection, or lymphadenopathy. Laboratory results, however, revealed elevated inflammatory markers with markedly elevated ferritin levels, acute phase reactants, hypoalbuminemia, elevated relic count but unremarkable hemolysis profile. Anti-neutrophil antibody titer, rheumatoid factor, anti-cyclic citrullinated peptide, blood cultures, and Lyme panels were negative.

At this point, he was referred to rheumatology for further evaluation and workup. Despite the lack of cranial symptoms, given the unusual relatively rapid onset of systemic inflammatory symptoms, as well as ruling out most of the other chronic inflammatory conditions, a suspicion of large vessel vasculitis was strongly considered. Other vasculitis syndromes were also ruled out by negative myeloperoxidase and PR-3 antineutrophil cytoplasmic antibody serologies. Results of a right temporal artery biopsy revealed

intimal thickening and a disrupted internal elastic lamina. There was resolution of the patient's symptoms with high doses of prednisone. He was switched to tocilizumab and symptoms remained controlled.

Resultant hyperglycemia was managed adequately with adjustments to his insulin regimen. See Table 1 for summary of lab results. 


\section{Cureus}

\begin{tabular}{|c|c|c|}
\hline Parameter & Value & Reference value \\
\hline Hemoglobin & 9.4 & $13.5-17.5 \mathrm{~g} / \mathrm{L}$ \\
\hline Hematocrit & 30 & $41-53 \%$ \\
\hline Leukocyte count & 17.9 & $4500-11,000 / \mathrm{mm}^{3}$ \\
\hline Erythrocyte count & 3.1 & 4.3-5.9 million $/ \mathrm{mm}^{3}$ \\
\hline Prothrombin time & 6.8 & 11-15 seconds \\
\hline Mean corpuscular volume & 97 & $80-100 u^{3}$ \\
\hline Mean corpuscular hemoglobin & 30.3 & 25-35 pg/cell \\
\hline Mean corpuscular hemoglobin concentration & 31 & $31-36 \% \mathrm{Hb} / \mathrm{cell}$ \\
\hline Red cell distribution width & 14.7 & $11.8-14.5 \%$ \\
\hline Platelet count & 631,000 & $150,000-400,000 / \mathrm{mm}^{3}$ \\
\hline C-reactive protein & 26.1 & $<3.0$ \\
\hline Ferritin & 1653 & 24-336 ug/L \\
\hline Creatinine & 0.9 & $0.6-1.2 \mathrm{mg} / \mathrm{dL}$ \\
\hline Urea & 19 & 7-18 mg/dL \\
\hline Sodium & 129 & 136-146 mEq/L \\
\hline Potassium & 4.7 & 3.5-5.0 mEq/L \\
\hline Chloride & 92 & 95-105 mEq/L \\
\hline Bicarbonate & 25 & $22-28 \mathrm{mEq} / \mathrm{L}$ \\
\hline Calcium & 9.1 & 8.4-10.2 mg/dL \\
\hline Glucose & 586 & $70-99$ mg/dL \\
\hline Albumin & 2.8 & $3.4-5.4 \mathrm{~g} / \mathrm{dL}$ \\
\hline Erythrocyte sedimentation rate & $>140$ & $0-15 \mathrm{~mm} / \mathrm{h}$ \\
\hline Alkaline phosphatase & 97 & 25-100 U/L \\
\hline Alanine aminotransferase & 15 & 10-40 U/L \\
\hline Aspartate aminotransferase & 24 & $12-38 \mathrm{U} / \mathrm{L}$ \\
\hline Total bilirubin & 0.2 & $0.1-0.2 \mathrm{mg} / \mathrm{dL}$ \\
\hline Proteinase 3 anti-neutrophil cytoplasmic antibodies & Non-reactive & 0-19 AU/mL \\
\hline Myeloperoxidase antibody & Non-reactive & 0-19 AU/mL \\
\hline Anti-nuclear antibody & 0.2 & 1:80 \\
\hline Rheumatoid factor & 18 & $0-20 \mathrm{IU} / \mathrm{mL}$ \\
\hline Anti-cyclic citrullinated peptide & Non-reactive & $<20 \mathrm{u} / \mathrm{mL}$ \\
\hline
\end{tabular}

TABLE 1: Summary of Lab Results

\section{Discussion}

\section{Pathophysiology}

The pathogenesis of GCA is poorly understood. Activation of immature dendritic cells within the tunica adventitia of the vessels leads to activation and proliferation of $\mathrm{CD} 4^{+}$naive T-cells. These cells then 
differentiate into T helper (Th)1, Th17, and T (Treg) regulatory cells. Macrophages produce metalloproteinases that lead to the destruction of the lamina Intima. A cascade of reactions occur in which reactive oxidation and production of various growth factors, including the release of interleukin (IL)-6, IL-8, and interferon-gamma, lead to vascular inflammation and damage with resultant obliteration and blockage. This is further worsened by dysregulated vascular repair. HLA DR-01 is thought to play a role and thus suggestive of antigen selection and presentation phenomena [10].

\section{Diagnosis}

Laboratory findings could be non-specific; however, the elevated inflammatory markers erythrocyte sedimentation rate/C-reactive protein, reactive transaminitis, thrombocytosis, and anemia are common in most patients. The utilization of the American College of Rheumatology classification criteria (1990) is helpful in differentiating various other types of vasculitis. The definitive diagnosis of GCA is made via histopathologic findings on temporal arterial biopsy, which is considered the gold standard, and this led us to the diagnosis in this case. Histologic changes include presence of polynucleated giant cells with inflammatory infiltration of the vascular media-intima interspaces, bridging of the internal elastic lamina layer with resultant part or total occlusion of blood supply to the involved region, and subsequent clinical consequences [11,12]. Sensitivity of above $90 \%$ has been associated with the use of color duplex ultrasonography as a non-invasive, easily accessible diagnosis tool especially with the revelation of arterial wall swelling (Halo sign). However, results are largely operator dependent and sensitivity is usually obscured in patients with underlying atherosclerosis $[13,14]$. Although the temporal arterial biopsy was the most useful diagnostic tool in this case, current advances in non-invasive methods of diagnosis via radiographic imaging have helped circumvent the limitations encountered when surgical specimens or biopsy is impractical. However, there remains divergent opinions on timing, tools for evaluation, and defining GCA. MRI, CT, and positron emission tomography (PET) scans have been used to aid the diagnosis of GCA with individually recognized pros and cons. MRI and MR angiography are reportedly very sensitive in visualizing vascular wall edema and also useful when wider sections of vascular involvement are being examined [13]. Evidence of aortitis was reported in $45-65 \%$ of patients newly diagnosed with GCA that were evaluated with CTA [14]. Subsequently, CTA studies have also reported aortic structural disruptions seen at the time of diagnosis in $15-23 \%$ of the patients. The fluorodeoxyglucose PET scan has been observed to show increased metabolic activity within the large arteries in up to $83 \%$ of patients with GCA. There is no PET criterion that currently defines the limits for vascular inflammation and/or prevent misinterpretation of vascular inflammation especially in the older population where vascular uptake could be exaggerated due to the presence of co-existing atherosclerosis [15].

\section{Management}

Glucocorticoids remain the treatment of choice in GCA, especially given its prompt anti-inflammatory properties that help control symptoms and avert serious adverse ischemic sequela. There are considerations and therapeutic recommendations that favor a shift toward steroid-sparing medications due to wellestablished risks of complications and adverse outcomes associated with steroid use [16]. Anti-platelet therapy like aspirin may be used to lower the risk of major adverse cardiovascular events [17]. Adjunctive therapies like methotrexate, and IL-6 inhibitors like tocilizumab have demonstrated significant clinical improvement and even sustained remission in most cases [18,19].

\section{Conclusions}

This patient had minimal symptoms indicative of GCA. However, a temporal biopsy revealed the typical findings in GCA. This case report highlights yet another symptomatology of GCA and emphasizes on the importance of biopsy as well as having a high index of suspicion. Diagnosis using PET scan is also a method that needs to be explored especially in older patients with signs of chronic long-standing atherosclerosis as in this patient.

\section{Additional Information \\ Disclosures}

Human subjects: Consent was obtained or waived by all participants in this study. Conflicts of interest: In compliance with the ICMJE uniform disclosure form, all authors declare the following: Payment/services info: All authors have declared that no financial support was received from any organization for the submitted work. Financial relationships: All authors have declared that they have no financial relationships at present or within the previous three years with any organizations that might have an interest in the submitted work. Other relationships: All authors have declared that there are no other relationships or activities that could appear to have influenced the submitted work.

\section{References}

1. Lensen KD, Voskuyl AE, Comans EF, van der Laken CJ, Smulders YM: Extracranial giant cell arteritis: a narrative review. Neth J Med. 2016, 74:182-92.

2. Dejaco C, Duftner C, Buttgereit F, Matteson EL, Dasgupta B: The spectrum of giant cell arteritis and polymyalgia rheumatica: revisiting the concept of the disease. Rheumatology (Oxford). 2017, 56:506-15. 
10.1093/rheumatology/kew273

3. González-Gay MA, García-Porrúa C, Llorca J, et al.: Visual manifestations of giant cell arteritis. Trends and clinical spectrum in 161 patients. Medicine (Baltimore). 2000, 79:283-92. 10.1097/00005792-20000900000001

4. Dasgupta B: Concise guidance: diagnosis and management of giant cell arteritis . Clin Med (Lond). 2010, 10:381-6. 10.7861/clinmedicine.10-4-381

5. Evans JM, O'Fallon WM, Hunder GG: Increased incidence of aortic aneurysm and dissection in giant cell (temporal) arteritis. A population-based study. Ann Intern Med. 1995, 122:502-7. 10.7326/0003-4819-122-7199504010-00004

6. Narváez J, Nolla-Solé JM, Narváez JA, Clavaguera MT, Valverde-García J, Roig-Escofet D: Musculoskeletal manifestations in polymyalgia rheumatica and temporal arteritis. Ann Rheum Dis. 2001, 60:1060-3.

7. Arnillas E, de la Fuente J, Núñez M, Domínguez F: Arteritis de células gigantes con afectación del epidídimo [Giant cell arteritis with epididymal involvement]. Med Clin (Barc). 2009, 132:485. 10.1016/j.medcli.2008.07.020

8. Patil A, Upadhyaya S, Kashyap V, Kumar R, Mishra N: An unusual case of giant cell arteritis with monoarthritis and orchitis at presentation. Arch Rheumatol. 2017, 32:268-70. 10.5606/ArchRheumatol.2017.626852

9. Sundaram S, Smith DH: Giant cell arteritis mimicking a testicular tumour. Rheumatol Int. 2001, 20:215-6. 10.1007/s002960100113

10. Ly KH, Régent A, Tamby MC, Mouthon L: Pathogenesis of giant cell arteritis: More than just an inflammatory condition?. Autoimmun Rev. 2010, 9:635-45. 10.1016/j.autrev.2010.05.002

11. Hunder GG, Bloch DA, Michel BA, et al.: The American College of Rheumatology 1990 criteria for the classification of giant cell arteritis. Arthritis Rheum. 1990, 33:1122-8. 10.1002/art.1780330810

12. Gonzalez-Gay MA: The diagnosis and management of patients with giant cell arteritis . J Rheumatol. 2005, 32:1186-8.

13. Muratore F, Pipitone N, Salvarani C, Schmidt WA: Imaging of vasculitis: state of the art . Best Pract Res Clin Rheumatol. 2016, 30:688-706. 10.1016/j.berh.2016.09.010

14. Prieto-González S, Arguis P, García-Martínez A, et al.: Large vessel involvement in biopsy-proven giant cell arteritis: prospective study in 40 newly diagnosed patients using CT angiography. Ann Rheum Dis. 2012, 71:1170-6. 10.1136/annrheumdis-2011-200865

15. Janssen SP, Comans EH, Voskuyl AE, Wisselink W, Smulders YM: Giant cell arteritis: heterogeneity in clinical presentation and imaging results. J Vasc Surg. 2008, 48:1025-31. 10.1016/j.jvs.2008.04.054

16. Prieto-González S, García-Martínez A, Tavera-Bahillo I, et al.: Effect of glucocorticoid treatment on computed tomography angiography detected large-vessel inflammation in giant-cell arteritis. A prospective, longitudinal study. Medicine (Baltimore). 2015, 94:e486. 10.1097/MD.0000000000000486

17. Martínez-Taboada VM, López-Hoyos M, Narvaez J, Muñoz-Cacho P: Effect of antiplatelet/anticoagulant therapy on severe ischemic complications in patients with giant cell arteritis: a cumulative meta-analysis. Autoimmun Rev. 2014, 13:788-94. 10.1016/j.autrev.2014.02.006

18. Spiera RF, Mitnick HJ, Kupersmith M, Richmond M, Spiera H, Peterson MG, Paget SA: A prospective, double-blind, randomized, placebo controlled trial of methotrexate in the treatment of giant cell arteritis (GCA). Clin Exp Rheumatol. 2001, 19:495-501.

19. Stone JH, Tuckwell K, Dimonaco S, et al.: Trial of tocilizumab in giant-cell arteritis . N Engl J Med. 2017, 377:317-28. 10.1056/NEJMoa1613849 